\title{
Estimativa da porosidade de argamassas de cimento e cal pelo método de cálculo de volumes
}

\author{
Porosity estimation of cement-lime mortar through the \\ volume calculation method
}

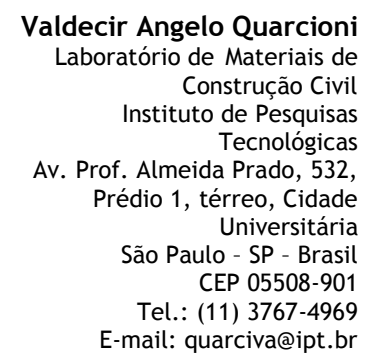

Fabiano Ferreira Chotoli Laboratório de Materiais de Construção Civil Instituto de Pesquisas Tecnológicas

E-mail: fchotoli@ipt.br

Sergio Cirelli Ângulo Laboratório de Materiais de Construção Civil Instituto de Pesquisas Tecnológicas

E-mail: scangulo@ipt.br

Mario Sergio Guilge Laboratório de Materiais de Construção Civil Instituto de Pesquisas Tecnológicas E-mail: msergio@ipt.br

Gilberto de Ranieri Cavani Laboratório de Materiais de Construção Civil Instituto de Pesquisas Tecnológicas E-mail: grcavani@ipt.br

Alessandra Lorenzetti de Castro Laboratório de Materiais de Construção Civil Instituto de Pesquisas Tecnológicas E-mail: alcastro@ipt.br

Maria Alba Cincotto Departamento de Engenharia de Construção Civil, Escola Politécnica

Universidade de São Paulo Av. Prof. Almeida Prado, Trav. 2, Ed. Engenharia Civil, Cidade Universitária São Paulo - SP - Brasil CEP05508-900

Tel.: (11) 3091-5792

E-mail: cincotto@poli.usp.br

\author{
Valdecir Angelo Quarcioni \\ Fabiano Ferreira Chotoli \\ Sergio Cirelli Ângulo \\ Mario Sergio Guilge \\ Gilberto de Ranieri Cavani \\ Alessandra Lorenzetti de Castro \\ Maria Alba Cincotto
}

\section{Resumo \\ $\Delta$}

presença de cal nas argamassas mistas é responsável pelo aumento na demanda de água de amassamento para uma dada consistência. A água adicional, que não é consumida na hidratação do cimento, permanece livre no sistema e, ao evaporar, dá origem a porosidade elevada da argamassa endurecida. Este trabalho apresenta o método do cálculo de volumes como uma ferramenta para estimar a porosidade de argamassas mistas a partir de seus constituintes, inclusive a cal, bem como sua correlação com propriedades relevantes no estado endurecido. O método apresentado mostrou-se favorável para a previsão de propriedades que definem o comportamento dos revestimentos de argamassa. Os dados apresentados sugerem continuidade e aprofundamento desta linha de estudo envolvendo aspectos não considerados no cálculo teórico de volume, tais como a influência da retração e da carbonatação nas argamassas.

Palavras-chave: Argamassa; Porosidade; Cálculo de volume; Resistência mecânica.

\section{Abstract}

The presence of lime in mixed mortars is responsible for the increase in the demand for mixing water for a given consistency. The additional water, which is not consumed in the cement hydration, remains free in the system and when evaporating it leads to high porosity in the hardened mortar. This paper presents the method of volume calculation as a tool for estimating the porosity of mixed mortars through their constituents, including lime, as well as its correlation with relevant properties in the hardened state. The method presented proved to be adequate for predicting the properties that define the behavior of the rendering. The data suggest that this approach needs further research, involving issues not considered in the theoretical volume calculation, such as the influence of shrinkage and carbonation.

Keywords: Mortar. Porosity. Volume calculation. Mechanical resistance. 


\section{Introdução}

A porosidade de um revestimento em argamassa está intrinsecamente ligada a sua composição, a seu procedimento de aplicação e ao processo de cura adotado, bem como à porosidade e à textura da superfície sobre a qual é aplicada. Ela interfere na durabilidade do revestimento e tem particular importância por acumular umidade e propiciar o crescimento de fungos. Submetida a argamassa a ciclos de molhagem e secagem, os sais dissolvidos cristalizam provocando expansão e fissuração do revestimento. Assim, os dados sobre a porosidade total de uma argamassa e o tipo e a distribuição de poros em sua microestrutura permitem inferir conclusões sobre os fenômenos que prejudicam o desempenho de determinado revestimento, assim como complementar as análises das propriedades mecânicas desses materiais (QUARCIONI et al., 2001).

Em geral, existe uma relação fundamental inversa entre a porosidade e a resistência mecânica de sólidos, que, para materiais homogêneos simples, pode ser descrita pela equação 1 (MEHTA; MONTEIRO, 2008).

$S=S_{o} e^{-k p}$

onde $S$ é a resistência do material que possui uma dada porosidade $p ; S_{o}$ é a resistência intrínseca para a porosidade zero; e $k$ é uma constante. Assim, diversos estudos relacionam a porosidade da pasta de cimento com a resistência mecânica dos materiais, o que foi confirmado e validado pelos estudos desenvolvidos por Ryshkewitch (BEAUDOIN; FELDMAN; TUMIDAJSLI, 1994).

De acordo com Powers, a resistência intrínseca de argamassas e concretos convencionais é de aproximadamente $230 \mathrm{MPa}$. Como os agregados normalmente utilizados na composição desses materiais possuem porosidade muito baixa e apresentam resistências mecânicas superiores a $130 \mathrm{MPa}$, a resistência de argamassas e concretos convencionais é definida pela porosidade da pasta de cimento hidratada somada aos defeitos presentes em sua microestrutura (MEHTA; MONTEIRO, 2008).

Assim, a formação de poros na pasta de cimento geralmente está associada à hidratação do cimento e à evaporação da água livre. $\mathrm{O}$ volume de vazios capilares na pasta de cimento endurecida depende da quantidade de água de amassamento adicionada no início da hidratação e do grau de hidratação do cimento. Quando se tem a pega do cimento, a pasta adquire um volume estável, que é aproximadamente igual ao volume de cimento mais o volume de água. Esse cálculo foi feito por Powers, a fim de demonstrar variações na porosidade capilar com diferentes graus de hidratação em pastas de cimento contendo diferentes relações água-cimento (MEHTA; MONTEIRO, 2008).

A quantidade de água quimicamente combinada é adotada como sendo correspondente a uma relação água-cimento de 0,23, podendo ser menor para cimentos compostos. Quando superior a esse valor, resulta em água livre (NEVILLE, 1997), que, não reagindo com o cimento, gera poros na microestrutura após sua evaporação, diminuindo sua resistência mecânica. Quanto menor for a razão entre o volume de sólidos e o volume de vazios, menor será a resistência mecânica (Figura $1)$.

Pelo gráfico da Figura 2, pode-se inferir que, com o aumento da relação água-cimento, há um aumento do volume de poros capilares. Esse efeito está associado à maior quantidade de água livre, não consumida na hidratação do cimento.

A cal hidratada é um material que apresenta uma área específica, em geral, superior à do cimento Portland. Em decorrência dessa característica, a cal, ao ser incorporada nas argamassas, exige um aumento na demanda de água de amassamento para manter uma mesma consistência. Essa água adicional, que não é consumida na hidratação do cimento, permanecerá livre no sistema e, ao evaporar, implicará uma maior porosidade da argamassa endurecida.

Assim, uma questão fundamental é a influência da presença de cal na porosidade das argamassas mistas e nas propriedades decorrentes, o que foi discutido a partir de dados experimentais apresentados por Quarcioni e Cincotto (2005). 0 trabalho referido avaliou argamassas simples de cal e de cimento em comparação com argamassas mistas produzidas com os mesmos materiais. Verificou-se um consumo crescente de água de amassamento com o aumento do teor de cal para uma consistência fixa de $260 \mathrm{~mm} \pm 5 \mathrm{~mm}$, o que implica o aumento proporcional da porosidade das respectivas argamassas endurecidas. Por outro lado, a incorporação de cal em argamassas de revestimento tem um apelo favorável relacionado ao ganho de plasticidade no estado fluido e na deformabilidade das argamassas endurecidas.

O método do cálculo de volumes foi desenvolvido com a finalidade de se prever a porosidade das argamassas (ANTUNES, 2005; QUARCIONI et al., 2009), ou seja, o volume teórico de vazios é calculado a partir dos materiais constituintes da 
mistura, o qual pode ser posteriormente correlacionado às propriedades físicas do material quando no estado endurecido.

O cálculo de volumes para argamassas mistas de cimento e cal visa também evidenciar a contribuição da cal, vinculando-a ao aumento de vazios resultante da maior retenção de água e consequente evaporação de água "em excesso" na argamassa, e inferir sobre a permeabilidade dessas argamassas mistas. Em trabalhos precedentes, discutiu-se a influência da presença de cal em propriedades mecânicas das argamassas (QUARCIONI; CINCOTTO, 2005), bem como a caracterização de sua porosidade, vinculando-a à natureza da cal (QUARCIONI et al., 2001) e à permeabilidade ao ar, em função de variações na relação água-aglomerante e no grau de carbonatação da argamassa (QUARCIONI et al., 2007).

\section{Objetivo}

O artigo tem como objetivo apresentar o método do cálculo de volumes para previsão da porosidade de argamassas mistas de cimento e cal. Para a verificação da aplicabilidade do método proposto, a porosidade calculada foi correlacionada com propriedades relevantes de argamassas no estado endurecido, ou seja, índice de vazios, absorção de água, resistência à compressão e resistência à tração na flexão.

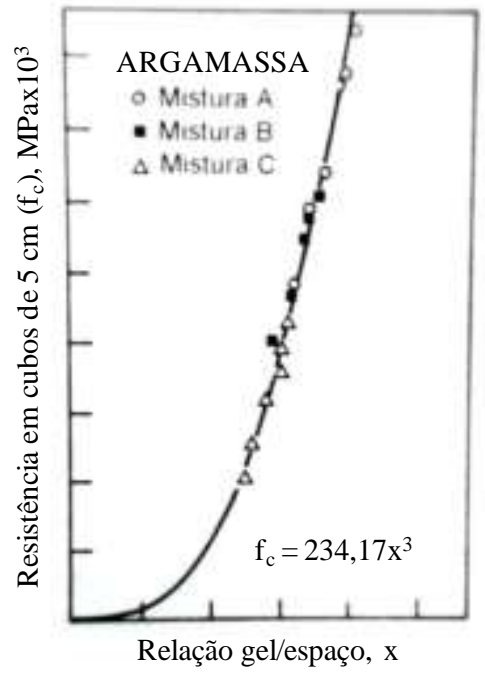

Fonte: Mehta e Monteiro (2008)

Figura 1 - Relação porosidade-resistência em argamassas de cimento Portland com diferentes dosagens

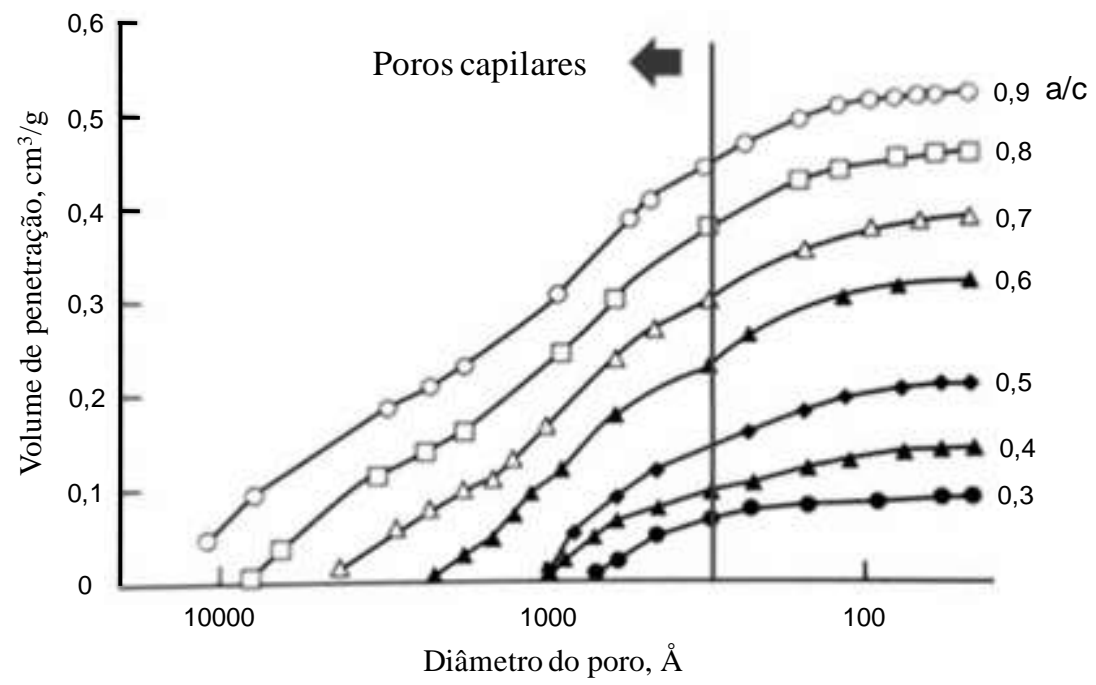

Fonte: Mehta e Monteiro (2008) 
Figura 2 - Distribuição de tamanhos de poros na pasta de cimento hidratada em função da relação águacimento

\section{Tratamento dos dados experimentais}

No contexto do desenvolvimento deste trabalho foram avaliadas argamassas mistas de cimento Portland composto (CPII E 32) e dois tipos de cal hidratada (tipo $\mathrm{CH}$ I, cálcica, e tipo $\mathrm{CH}$ III, dolomítica), conforme Quarcioni (1998). Diversos traços de argamassas foram produzidos para ambas as cales (1:1:6, 1:2:9, 1:1:8 e 1:1:12). A areia utilizada na composição das argamassas mistas de cimento e cal corresponde à areia normal do IPT, uma areia essencialmente quartzosa, cuja distribuição granulométrica foi composta em laboratório, a fim de se estabelecer uma distribuição contínua. A composição química do cimento e das cales bem como suas características físicas são apresentadas nas Tabelas 1 e 2 respectivamente. A curva de distribuição granulométrica da areia é apresentada na Figura 3.

As argamassas foram produzidas de acordo com as recomendações da NBR 13276 (ABNT, 2005b), sem maturação prévia da pasta de cal, em um misturador com 5 litros de capacidade. A quantidade de água de mistura foi definida em função de um índice de consistência preestabelecido, de $260 \mathrm{~mm} \pm 5 \mathrm{~mm}$. As propriedades das argamassas no estado fresco são apresentadas na Tabela 3.

\begin{tabular}{|c|c|c|c|c|c|}
\hline \multirow[t]{2}{*}{ Constituintes } & \multicolumn{3}{|c|}{ (QUARCIONI, 1998) } & \multicolumn{2}{|c|}{ (SILVA, 2006) } \\
\hline & $\begin{array}{l}\text { Cimento } \\
\text { (CPII E } \\
\text { 32) }\end{array}$ & $\begin{array}{c}\text { Cal } \\
\text { calcítica } \\
\text { (CH I) }\end{array}$ & $\begin{array}{c}\text { Cal } \\
\text { dolomítica } \\
\text { (CH III) }\end{array}$ & $\begin{array}{c}\text { Cimento } \\
\text { (CPII Z 32) }\end{array}$ & $\begin{array}{c}\text { Cal virgem } \\
\text { especial } \\
\text { (CV-E) }\end{array}$ \\
\hline $\mathrm{SiO}_{2}(\%)$ & 20,5 & --- & --- & 22,91 & --- \\
\hline $\mathrm{Al}_{2} \mathrm{O}_{3}(\%)$ & 6,04 & \multirow{2}{*}{0,70} & \multirow{2}{*}{0,70} & 7,25 & NP \\
\hline $\mathrm{Fe}_{2} \mathrm{O}_{3}(\%)$ & 2,30 & & & 3,18 & NP \\
\hline $\mathrm{CaO}(\%)$ & 57,2 & 70,8 & 38,3 & 52,29 & 51,0 \\
\hline $\operatorname{MgO}(\%)$ & 4,42 & 0,42 & 26,5 & 5,56 & 35,6 \\
\hline $\mathrm{SO}_{3}(\%)$ & 2,82 & 0,23 & 0,10 & 2,82 & NP \\
\hline $\mathrm{CO}_{2}(\%)$ & 4,33 & 3,75 & 14,2 & 4,23 & 3,60 \\
\hline $\mathrm{Na}_{2} \mathrm{O}(\%)$ & 0,09 & --- & --- & 0,18 & --- \\
\hline $\mathrm{K}_{2} \mathrm{O}(\%)$ & 0,69 & --- & --- & 1,04 & --- \\
\hline $\mathrm{Na}_{2} \mathbf{O}_{\text {(equivalente) }}(\%)$ & 0,54 & --- & --- & 0,86 & -- \\
\hline $\begin{array}{l}\text { Óxidos totais }(\%) \\
(\mathrm{CaO}+\mathrm{MgO})\end{array}$ & --- & 96,8 & 90,1 & --- & 91,4 \\
\hline Perda ao fogo (\%) & 5,90 & 26,4 & 28,0 & 4,97 & 5,30 \\
\hline $\begin{array}{c}\text { Resíduo insolúvel } \\
(\%)\end{array}$ & 0,70 & 1,26 & 6,05 & 12,91 & 6,30 \\
\hline Umidade (\%) & --- & 0,06 & 0,39 & --- & NP \\
\hline
\end{tabular}

Legenda: NP - valor não publicado em Silva (2006)

Tabela 1 - Composição química do cimento e das cales constituintes das argamassas mistas 


\begin{tabular}{|c|c|c|c|c|c|}
\hline \multirow[b]{2}{*}{ Ensaios físicos } & \multicolumn{3}{|c|}{ (QUARCIONI, 1998) } & \multicolumn{2}{|c|}{ (SILVA, 2006) } \\
\hline & $\begin{array}{c}\text { Cimento } \\
(\text { CPII E 32) }\end{array}$ & $\begin{array}{l}\text { Cal calcítica } \\
\text { (CH I) }\end{array}$ & $\begin{array}{c}\text { Cal dolomítica } \\
\text { (CH III) }\end{array}$ & $\begin{array}{c}\text { Cimento } \\
(\text { CPII Z 32) }\end{array}$ & $\begin{array}{c}\text { Cal virgem } \\
\text { especial } \\
\text { (CV-E) }\end{array}$ \\
\hline $\begin{array}{l}\text { Massa específica } \\
\quad\left(\mathrm{g} / \mathrm{cm}^{3}\right)\end{array}$ & 3,02 & 2,31 & 2,45 & 2,95 & 2,39 \\
\hline Área específica $\left(\mathbf{m}^{2} / \mathbf{k g}\right)$ & 366 & --- & --- & NP & --- \\
\hline $\begin{array}{c}\text { Finura }(\%) \\
\# 30 \\
\# \mathbf{2 0 0} \\
\# 325\end{array}$ & $\begin{array}{l}--- \\
--- \\
5,8\end{array}$ & $\begin{array}{l}0,00 \\
6,30 \\
---\end{array}$ & $\begin{array}{c}0,05 \\
11,9 \\
---\end{array}$ & NP & NP \\
\hline $\begin{array}{l}\text { Água para pasta de } \\
\text { consistência normal } \\
\text { (\% massa do cimento) }\end{array}$ & 26,1 & --- & --- & NP & NP \\
\hline $\begin{array}{l}\text { Fator água-cal, em } \\
\text { massa }(\mathrm{g} / \mathrm{g})\end{array}$ & --- & 0,830 & 0,470 & $\mathrm{NP}$ & 0,754 \\
\hline Retenção de água (\%) & --- & 80 & 82 & NP & NP \\
\hline $\begin{array}{l}\text { Tempos de pega (min) } \\
\text { Início } \\
\text { Fim }\end{array}$ & $\begin{array}{l}265 \\
345\end{array}$ & --- & --- & NP & NP \\
\hline $\begin{array}{c}\text { Resistência à } \\
\text { compressão } \\
3 \text { dias (MPa) } \\
7 \text { dias (MPa) } \\
28 \text { dias (MPa) }\end{array}$ & $\begin{array}{l}18,0 \\
24,3 \\
32,6\end{array}$ & $\begin{array}{l}--- \\
--- \\
---\end{array}$ & $\begin{array}{l}--- \\
--- \\
---\end{array}$ & NP & NP \\
\hline
\end{tabular}

Legenda: NP - valor não publicado em Silva (2006)

Tabela 2 - Características físicas do cimento e das cales constituintes das argamassas mistas

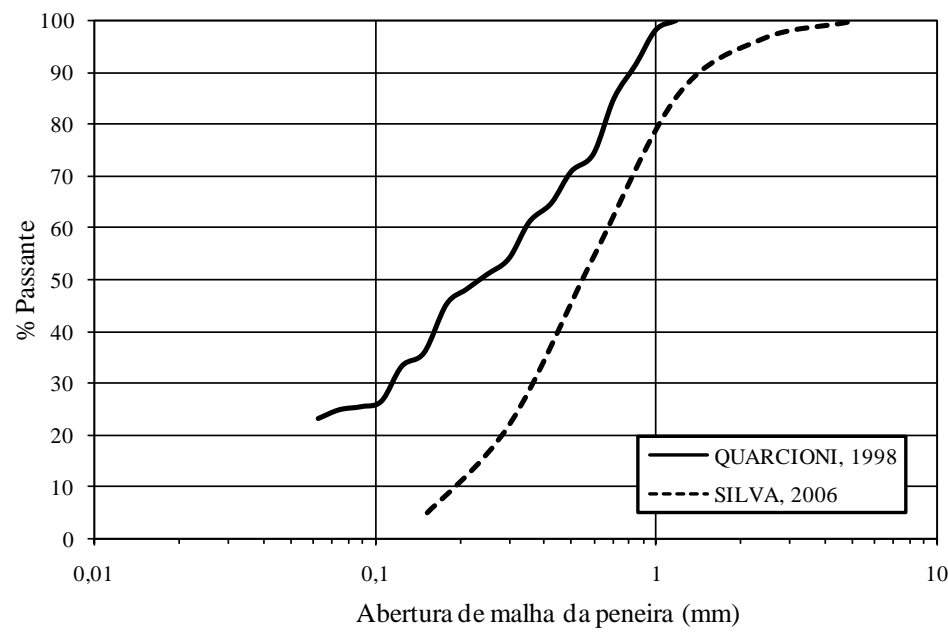

Figura 3 - Distribuição granulométrica da areia constituinte das argamassas mistas 


\begin{tabular}{|c|c|c|c|c|c|}
\hline Referência & $\begin{array}{c}\text { Argamassas } \\
\text { (traços em } \\
\text { volume) }\end{array}$ & $\begin{array}{l}\text { Relação água- } \\
\text { aglomerante }\end{array}$ & $\begin{array}{c}\text { Índice de } \\
\text { consistência (mm) } \\
\text { NBR 13276 } \\
\text { (ABNT, 2005b) }\end{array}$ & $\begin{array}{c}\text { Densidade de } \\
\text { massa }\left(\mathrm{g} / \mathrm{cm}^{3}\right) \\
\text { NBR 13278 } \\
(A B N T, 2005 c)\end{array}$ & $\begin{array}{c}\text { Teor de ar } \\
\text { incorporado* } \\
(\%) \\
\text { NBR 13278 } \\
\text { (ABNT, 2005c) }\end{array}$ \\
\hline \multirow{8}{*}{ 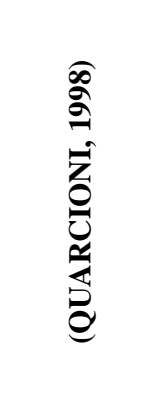 } & 1:1:6 CC & 0,86 & 264 & 2,05 & 4,4 \\
\hline & $1: 2: 9 \mathrm{CC}$ & 0,94 & 264 & 2,04 & 4,3 \\
\hline & $1: 1: 8 \mathrm{CC}$ & 1,09 & 261 & 2,04 & 4,6 \\
\hline & $1: 2: 12 \mathrm{CC}$ & 1,22 & 263 & 2,03 & 4,4 \\
\hline & 1:1:6 CD & 0,82 & 264 & 2,06 & 4,0 \\
\hline & $1: 2: 9 \mathrm{CD}$ & 0,91 & 260 & 2,04 & 3,9 \\
\hline & 1:1:8 CD & 1,06 & 263 & 2,04 & 4,5 \\
\hline & $1: 2: 12 \mathrm{CD}$ & 1,18 & 265 & 2,05 & 3,1 \\
\hline \multirow{9}{*}{ 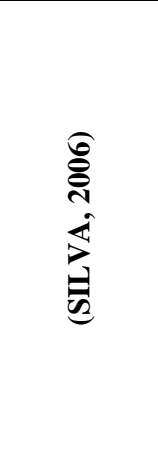 } & 1:1:4 CV-E & 1,00 & 260 & 2,00 & 0,26 \\
\hline & 1:1:6 CV-E & 1,37 & 270 & 1,99 & 1,04 \\
\hline & 1:1:8 CV-E & 1,74 & 265 & 1,96 & 2,53 \\
\hline & 1:2:6 CV-E & 1,27 & 265 & 1,93 & 0,05 \\
\hline & 1:2:9 CV-E & 1,57 & 270 & 1,93 & 2,51 \\
\hline & $1: 2: 12$ CV-E & 2,07 & 280 & 1,92 & 2,37 \\
\hline & 1:3:8 CV-E & 1,42 & 270 & 1,89 & 0,38 \\
\hline & 1:3:12 CV-E & 1,80 & 265 & 1,91 & 1,40 \\
\hline & 1:3:16 CV-E & 2,25 & 260 & 1,92 & 1,47 \\
\hline
\end{tabular}

" Teor de ar incorporado determinado pelo método pressométrico Legenda: CV-E: Cal virgem especial

CC: Cal hidratada cálcica

CD: Cal hidratada dolomitica

Tabela 3 - Parâmetros das argamassas mistas de cimento e cal no estado fresco

Para a realização dos ensaios no estado endurecido, foram moldados corpos de prova prismáticos de $(40 \times 40 \times 160) \mathrm{mm}$. Os corpos de prova foram curados seguindo um regime de cura cíclico, cinco dias em ambiente de laboratório $\left(\mathrm{T}_{\text {média }}=25{ }^{\circ} \mathrm{C}, \mathrm{H}_{\text {média }}=70 \%\right)$ e dois dias em câmara úmida $\left(\mathrm{T}=23{ }^{\circ} \mathrm{C}, \mathrm{H}=95 \%\right)$, a fim de simular uma condição característica de clima quente e úmido, com elevados índices pluviométricos.

As propriedades no estado endurecido foram avaliadas após 92 dias de cura, medindo-se o índice de vazios, a absorção por imersão e as resistências à compressão e à tração na flexão, de acordo com a NBR 9778 (ABNT, 2005a), NBR 15259 (ABNT, 2005e) e NBR 13279 (ABNT, 2005d) respectivamente. Essas propriedades foram correlacionadas com o volume teórico de vazios determinados a partir do cálculo de volumes dos constituintes das argamassas mistas; assim, foi possível verificar a correlação entre o cálculo teórico de vazios e as propriedades medidas.

\section{Método do cálculo de volumes}

O método do cálculo de volumes proposto tem sua utilidade em estimar a porosidade da argamassa, prevendo suas propriedades fundamentais com base em seus constituintes, inclusive a cal. O método é dividido em quatro etapas principais, sendo:

(a) etapa 1: conversão do traço em volume para traço em massa, tendo como base as massas unitárias dos materiais constituintes; os materiais são separados em cimento, cal hidratada, fíler calcário, areia, água de hidratação do cimento e água evaporável;

(b) etapa 2: conversão da porcentagem em massa para porcentagem em volume, com base nas massas específicas dos materiais e considerando o volume correspondente à incorporação de ar, para o estado fresco;

(c) etapa 3: cálculo porcentual dos componentes da argamassa no estado fresco; e

180 Quarcioni, V. A.; Chotoli, F. F.; Ângulo, S. C.; Guilge, M. S.; Cavani, G. de R.; Castro, A. L. de; Cincotto, M. 
(d) etapa 4: cálculo da porcentagem dos componentes da argamassa no estado endurecido.

\section{Resultados e discussões}

\section{Volume teórico de vazios determinado a partir do método do cálculo de volumes}

Na etapa 1, fez-se a conversão do traço em volume para o traço em massa, tendo como base as massas unitárias dos materiais constituintes (Tabela 4).

Os materiais constituintes das argamassas mistas foram separados em cal, fíler calcário, areia, água de hidratação do cimento $\left(\mathrm{H}_{2} \mathrm{O}_{\mathrm{AH}}\right)$ e água evaporável $\left(\mathrm{H}_{2} \mathrm{O}_{\mathrm{AE}}\right)$. $\mathrm{O}$ fíler calcário total é dado pela soma do fíler presente no cimento e na cal (residual), cujas quantidades foram determinadas por análise química e correspondem a 9,83\%, $8,51 \%$ e $29,73 \%$ para o cimento, cal cálcica e cal dolomítica respectivamente. A quantidade de água destinada à hidratação do cimento foi adotada como sendo igual a $23 \%$ da massa de cimento (água combinada teórica). Assim, na Tabela 5, são apresentados os traços em massa das argamassas mistas em função dos materiais constituintes, retirando-se o fíler do cimento e da cal e separando-se a água combinada.

$\mathrm{Na}$ etapa 2, o traço em massa foi convertido para traço em volume, tendo como base as massas específicas dos materiais. Os resultados dessa conversão são apresentados na Tabela 6 .

\begin{tabular}{|c|c|c|c|c|c|c|c|c|}
\hline \multirow{2}{*}{ Argamassas } & \multicolumn{3}{|c|}{ Traço em massa } & \multirow{2}{*}{$\begin{array}{l}\text { Somatória } \\
\text { mat. secos }\end{array}$} & \multirow{2}{*}{ a/agl } & \multirow{2}{*}{$\begin{array}{c}\text { Teor de ar } \\
\text { incorporado }\end{array}$} & \multirow{2}{*}{$\begin{array}{l}\text { Quantidade } \\
\text { de água }\end{array}$} & \multirow{2}{*}{$\underset{(\%)}{\mathbf{H}}$} \\
\hline & Cimento & Cal & Areia & & & & & \\
\hline 1:1:6 CC & 1 & 0,47 & 5,82 & 7,29 & 0,86 & 4,4 & 1,264 & 17,3 \\
\hline 1:2:9 CC & 1 & 0,95 & 8,73 & 10,68 & 0,94 & 4,3 & 1,833 & 17,2 \\
\hline 1:1:8 CC & 1 & 0,47 & 7,76 & 9,23 & 1,09 & 4,6 & 1,602 & 17,4 \\
\hline $1: 2: 12 \mathrm{CC}$ & 1 & 0,95 & 11,6 & 13,55 & 1,22 & 4,4 & 2,379 & 17,6 \\
\hline 1:1:6 CD & 1 & 0,56 & 5,82 & 7,38 & 0,82 & 4,0 & 1,279 & 17,3 \\
\hline 1:2:9 CD & 1 & 1,13 & 8,73 & 10,86 & 0,91 & 3,9 & 1,938 & 17,8 \\
\hline 1:1:8 CD & 1 & 0,56 & 7,76 & 9,32 & 1,06 & 4,5 & 1,654 & 17,7 \\
\hline 1:2:12 CD & 1 & 1,13 & 11,6 & 13,73 & 1,18 & 3,1 & 2,513 & 18,3 \\
\hline
\end{tabular}

Legenda: a/agl: relação água-aglomerante

$\mathrm{H}$ : relação água-materiais secos

CC: Cal hidratada cálcica

CD: Cal hidratada dolomitica

Tabela 4 - Dados de entrada e conversão da água para a relação água-materiais secos $(\mathrm{H})$

\begin{tabular}{|c|c|c|c|c|c|c|c|c|c|}
\hline Argamassas & $\begin{array}{l}\text { Fíler do } \\
\text { cimento }\end{array}$ & $\begin{array}{c}\text { Fíler da } \\
\text { cal }\end{array}$ & $\begin{array}{l}\text { Fíler } \\
\text { total }\end{array}$ & Cimento & Cal & Areia & Água & $\begin{array}{c}\text { Água } \\
\text { combinada }\end{array}$ & $\begin{array}{c}\text { Água } \\
\text { evaporável }\end{array}$ \\
\hline 1:1:6 CC & 0,0983 & 0,0400 & 0,1383 & 0,9017 & 0,4300 & 5,82 & 1,264 & 0,207 & 1,057 \\
\hline $1: 2: 9 \mathrm{CC}$ & 0,0983 & 0,0809 & 0,1792 & 0,9017 & 0,8691 & 8,73 & 1,833 & 0,207 & 1,626 \\
\hline 1:1:8 CC & 0,0983 & 0,0400 & 0,1383 & 0,9017 & 0,4300 & 7,76 & 1,602 & 0,207 & 1,395 \\
\hline $1: 2: 12 \mathrm{CC}$ & 0,0983 & 0,0809 & 0,1792 & 0,9017 & 0,8691 & 11,6 & 2,379 & 0,207 & 2,172 \\
\hline 1:1:6 CD & 0,0983 & 0,1665 & 0,2648 & 0,9017 & 0,3935 & 5,82 & 1,279 & 0,207 & 1,072 \\
\hline $1: 2: 9 \mathrm{CD}$ & 0,0983 & 0,3360 & 0,4343 & 0,9017 & 0,7940 & 8,73 & 1,938 & 0,207 & 1,731 \\
\hline 1:1:8 CD & 0,0983 & 0,1665 & 0,2648 & 0,9017 & 0,3935 & 7,76 & 1,654 & 0,207 & 1,446 \\
\hline $1: 2: 12 \mathrm{CD}$ & 0,0983 & 0,3360 & 0,4343 & 0,9017 & 0,7940 & 11,6 & 2,513 & 0,207 & 2,306 \\
\hline
\end{tabular}

Tabela 5 - Traços em massa das argamassas mistas considerando-se separadamente os materiais constituintes 


\begin{tabular}{c|c|c|c|c|c|c|c|c}
\hline Argamassas & Fíler & Cimento & Cal & Areia & Água & $\begin{array}{c}\text { Água } \\
\text { combinada }\end{array}$ & $\begin{array}{c}\text { Água } \\
\text { evaporável }\end{array}$ & Total \\
\hline $1: 1: 6 \mathrm{CC}$ & 0,051 & 0,299 & 0,186 & 2,196 & 1,264 & 0,207 & 1,057 & 3,996 \\
\hline $1: 2: 9 \mathrm{CC}$ & 0,066 & 0,299 & 0,376 & 3,294 & 1,833 & 0,207 & 1,626 & 5,868 \\
\hline $1: 1: 8 \mathrm{CC}$ & 0,051 & 0,299 & 0,186 & 2,928 & 1,602 & 0,207 & 1,395 & 5,066 \\
\hline $1: 2: 12 \mathrm{CC}$ & 0,066 & 0,299 & 0,376 & 4,377 & 2,379 & 0,207 & 2,172 & 7,497 \\
\hline $1: 1: 6 \mathrm{CD}$ & 0,098 & 0,299 & 0,161 & 2,196 & 1,279 & 0,207 & 1,072 & 4,032 \\
\hline $1: 2: 9 \mathrm{CD}$ & 0,160 & 0,299 & 0,324 & 3,294 & 1,938 & 0,207 & 1,731 & 6,016 \\
\hline $1: 1: 8 \mathrm{CD}$ & 0,098 & 0,299 & 0,161 & 2,928 & 1,654 & 0,207 & 1,446 & 5,139 \\
\hline $1: 2: 12 \mathrm{CD}$ & 0,160 & 0,299 & 0,324 & 4,377 & 2,513 & 0,207 & 2,306 & 7,674 \\
\hline
\end{tabular}

Legenda: CC: Cal hidratada cálcica

CD: Cal hidratada dolomitica.

Tabela 6 - Conversão do traço em massa para traço em volume

Na etapa 3, a porcentagem correspondente a cada material constituinte foi calculada. $O$ volume correspondente à incorporação de $\operatorname{ar}\left(\mathrm{Ar}_{\mathrm{AI}}\right)$ foi considerado para completar $100 \%$ da argamassa. As proporções da mistura (em volume) são apresentadas na Tabela 7 , enquanto uma ilustração do volume ocupado pelas frações dos materiais constituintes das argamassas mistas no estado fresco é apresentada na Figura 4.

Por fim, na etapa 4, as porcentagens do volume dos componentes das argamassas mistas quando no estado endurecido são calculadas a partir dos volumes ocupados pelos materiais constituintes quando no estado fresco. O cálculo é feito considerando-se as transformações apresentadas na Figura 5.

$\mathrm{Na}$ Figura 6, os volumes ocupados pelos componentes das argamassas mistas quando no estado endurecido são representados graficamente.

\section{Correlação entre as propriedades das argamassas mistas no estado endurecido e o volume teórico de vazios determinado pelo método do cálculo de volumes}

Para a determinação da correlação entre as propriedades das argamassas mistas no estado endurecido (QUARCIONI, 1998) e o volume teórico de vazios calculado pelo método do cálculo de volumes, além das argamassas produzidas e avaliadas no Instituto de Pesquisas Tecnológicas do Estado de São Paulo (IPT), as argamassas avaliadas no estudo desenvolvido por Silva (2006) também foram consideradas (identificadas pela sigla CV-E na legenda dos gráficos). A consideração de dados adicionais aos do IPT se deu pela busca por uma equação geral, de modo a abranger as diversas argamassas mistas produzidas nos diversos laboratórios de pesquisa e utilizadas, na prática, nas construções.

A partir do gráfico apresentado na Figura 7, verifica-se que a quantidade calculada de poros teóricos a partir do método do cálculo de volumes para as argamassas mistas é subestimada com relação à quantidade de poros medida por meio da determinação do índice de vazios desses materiais.

A diferença observada entre os valores medidos e calculados pode ser explicada pelas considerações adotadas no cálculo teórico. Assim, a quantidade de água quimicamente combinada considerada no cálculo foi um valor teórico, não sendo considerada a quantidade de água que combina com o cimento durante sua hidratação (determinação da água de gel quimicamente combinada com base em dados da hidratação do cimento). Da mesma forma, a retração química do cimento, que pode gerar vazios na microestrutura das argamassas, não foi considerada no cálculo teórico.

A consideração desses fatores, que interferem diretamente na quantidade de poros de sistemas cimentícios, ao serem considerados no cálculo teórico, poderiam resultar em coeficientes de correlação entre o índice de vazios medido e o volume de poros teóricos calculado próximos de 1 , como indicativo de que a quantidade de poros de uma argamassa mista pode ser prevista pelo método de cálculo de volumes dos constituintes das argamassas. 


\begin{tabular}{c|c|c|c|c|c|c|c|c}
\hline Argamassas & Ar & Fíler & $\begin{array}{c}\text { Cimento } \\
\text { anidro }\end{array}$ & Cal & Areia & Água & $\begin{array}{c}\text { Água } \\
\text { combinada }\end{array}$ & $\begin{array}{c}\text { Água } \\
\text { evaporável }\end{array}$ \\
\hline $1: 1: 6 \mathrm{CC}$ & 4,4 & 1,22 & 7,14 & 4,45 & 52,54 & 30,24 & 4,96 & 25,28 \\
\hline $1: 2: 9 \mathrm{CC}$ & 4,3 & 1,08 & 4,87 & 6,14 & 53,72 & 29,89 & 3,38 & 26,51 \\
\hline $1: 1: 8 \mathrm{CC}$ & 4,6 & 0,96 & 5,62 & 3,51 & 55,14 & 30,17 & 3,91 & 26,27 \\
\hline $1: 2: 12 \mathrm{CC}$ & 4,4 & 0,84 & 3,81 & 4,80 & 55,82 & 30,34 & 2,64 & 27,69 \\
\hline $1: 1: 6 \mathrm{CD}$ & 4,0 & 2,33 & 7,11 & 3,82 & 52,29 & 30,45 & 4,94 & 25,52 \\
\hline $1: 2: 9 \mathrm{CD}$ & 3,9 & 2,56 & 4,77 & 5,18 & 52,63 & 30,96 & 3,31 & 27,65 \\
\hline $1: 1: 8 \mathrm{CD}$ & 4,5 & 1,82 & 5,55 & 2,98 & 54,42 & 30,73 & 3,85 & 26,88 \\
\hline $1: 2: 12 \mathrm{CD}$ & 3,1 & 2,03 & 3,77 & 4,09 & 55,27 & 31,74 & 2,62 & 29,12 \\
\hline
\end{tabular}

Tabela 7 - Proporção (em volume) dos constituintes das argamassas, considerando o teor de ar incorporado

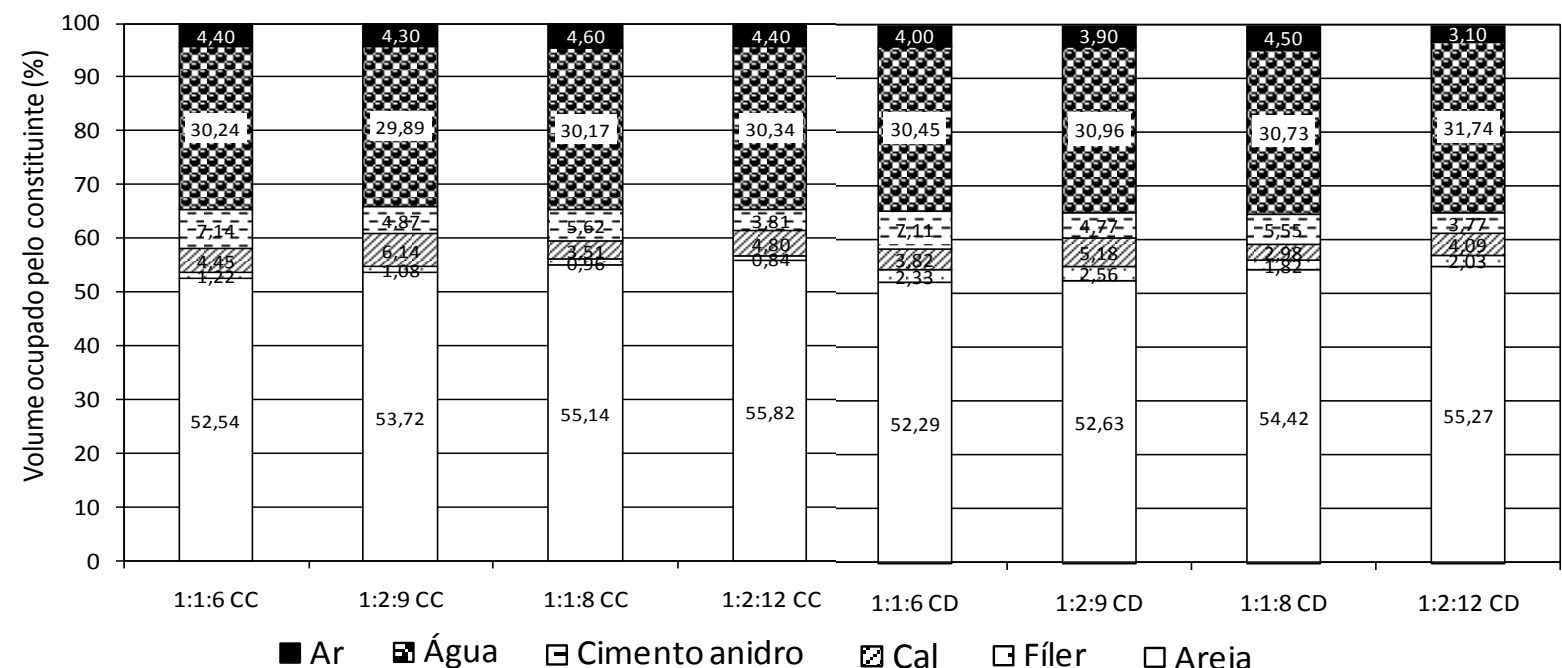

Figura 4 - Volume ocupado pelas frações dos materiais constituintes no estado fresco

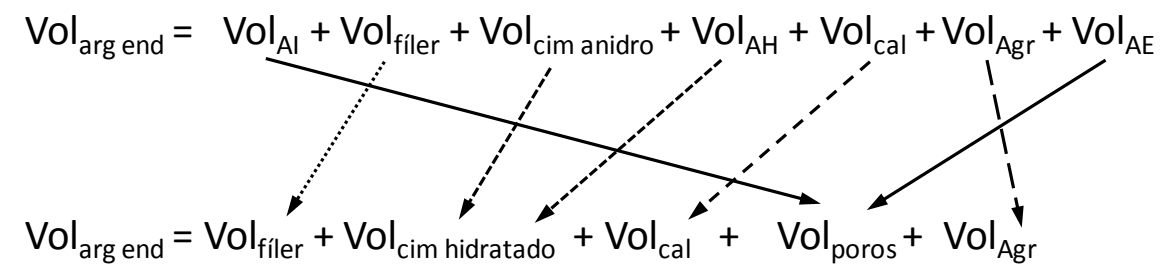

Legenda: Volarg end : volume de argamassa no estado endurecido

$\mathrm{Vol}_{\mathrm{Al}}$ : volume de ar incorporado

$V_{\text {Vol }}$ iler: volume total de fíler

Vol ${ }_{\text {cim anidro }}$ : volume de cimento anidro

Vol $_{A H}$ : volume da água de hidratação

Vol $_{\text {cal }}$ volume de cal

$\mathrm{Vol}_{\mathrm{Agr}}$ : volume de agregado (areia)

$\mathrm{Vol}_{\mathrm{AE}}$ : volume de água evaporável

Vol $_{\text {cim }}$ hidratado: é o volume de cimento hidratado

Vol ${ }_{\text {poros: }}$ volume de poros

Figura 5 - Cálculo das porcentagens do volume dos componentes das argamassas mistas 


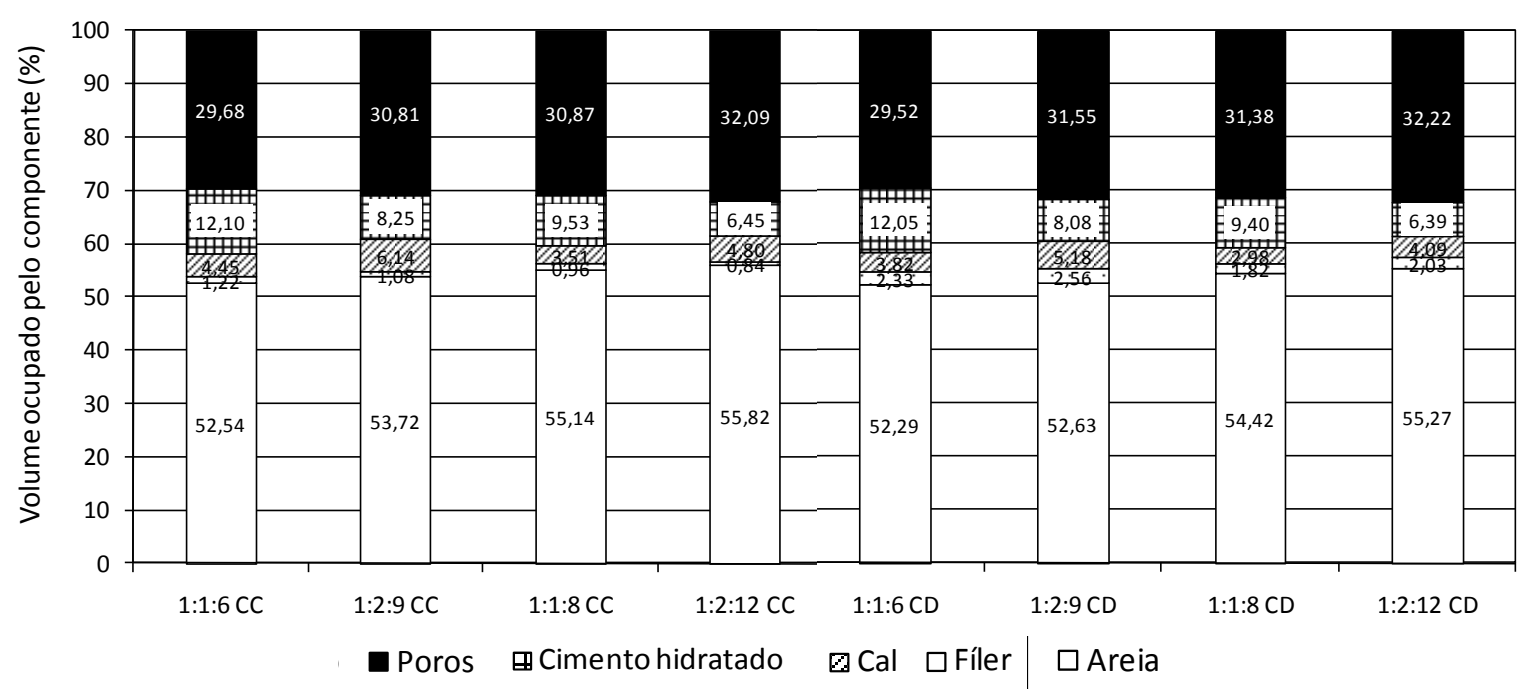

Figura 6 - Volume ocupado pelas frações dos componentes da argamassa no estado

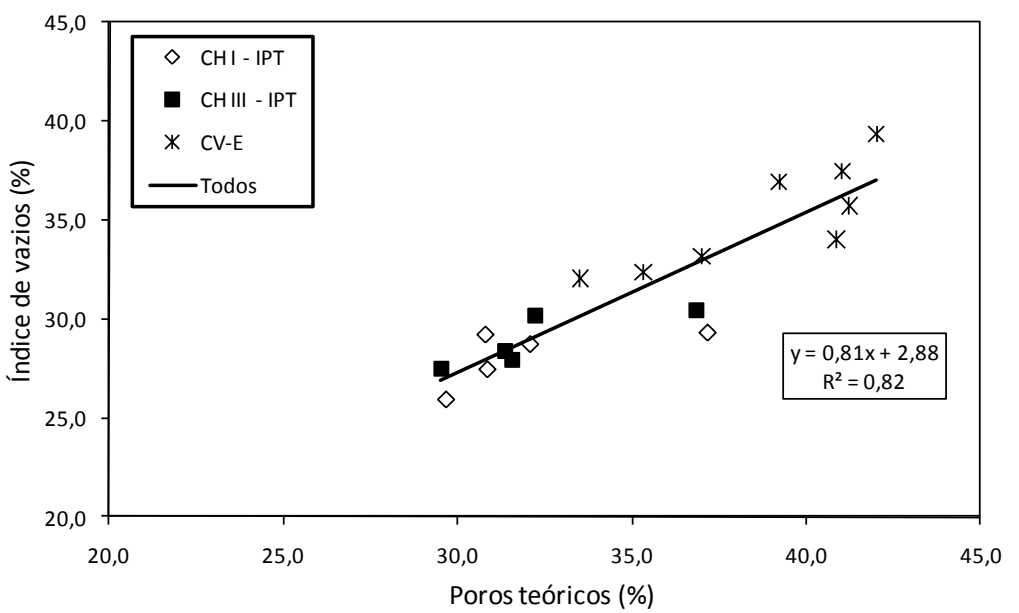

endurecido

Poros teóricos (\%)

Figura 7 - Correlação entre o índice de vazios e o volume de poros teóricos a partir dos volumes calculados

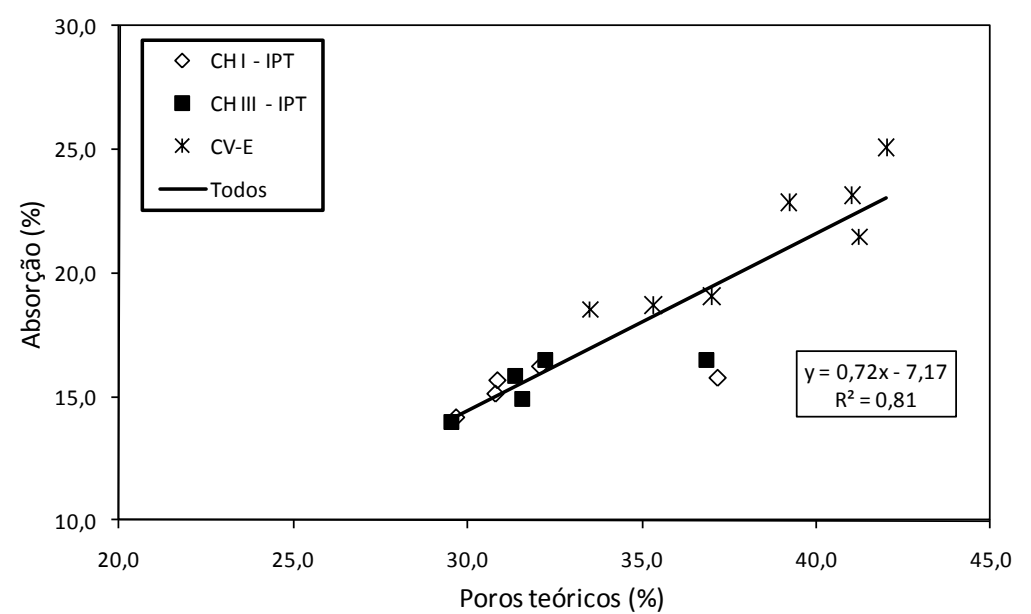

Figura 8 - Correlação entre a absorção de água medida e o volume de poros teóricos calculados

Os dados deste estudo indicam que há correlação entre a quantidade de poros teóricos e a de poros medidos para argamassas de cimento e cal, bem como entre a porosidade e a resistência mecânica (Figuras 7 e 8). Por analogia, o comportamento observado pode ser considerado compatível à Lei 
de Abrams, segundo a qual a resistência mecânica é inversamente proporcional à porosidade e ao consumo de água dos concretos.

A quantidade de água absorvida por um material está associada ao índice de vazios presentes em sua microestrutura, que, por sua vez, determina a permeabilidade do material. Como o volume de poros teóricos calculado foi menor do que o determinado experimentalmente, a correlação entre a absorção e o volume de poros teóricos $\left(\mathrm{R}^{2}=\right.$ 0,81 ) indicada na Figura 8 foi menor que a correção da absorção com o índice de vazios medido em laboratório $\left(\mathrm{R}^{2}=0,97\right)$ indicada na Figura 9. Após os ajustes necessários no cálculo, considerando a água quimicamente combinada efetiva e a retração do cimento, a correlação entre o cálculo teórico e o valor medido poderá ser melhorada.

Com relação às resistências à compressão e à tração na flexão, as correlações entre essas propriedades e a porosidade teórica determinada a partir do método do cálculo de volumes foram ajustadas por uma equação exponencial e são apresentadas nas Figuras 10 e 11 respectivamente.

A partir dos gráficos apresentados nas Figuras 10 e 11, verifica-se que a correlação entre as resistências e o volume de poros teóricos calculado pelo método apresentado obedece à relação inversa estabelecida na Equação 1, com coeficientes de correlação maiores que 0,85 .

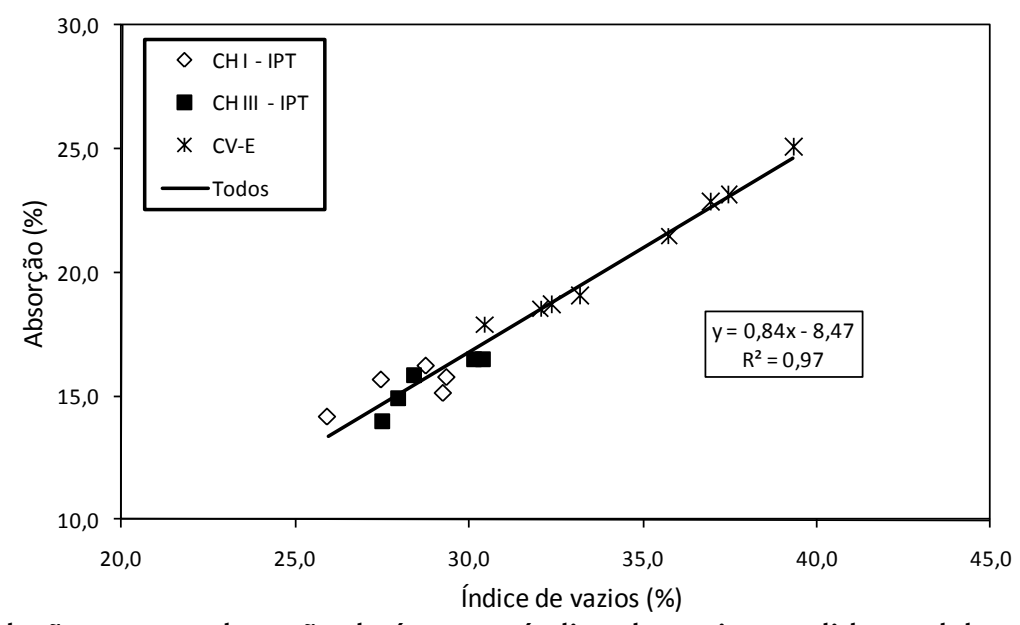

Figura 9 - Correlação entre a absorção de água e o índice de vazios medido em laboratório

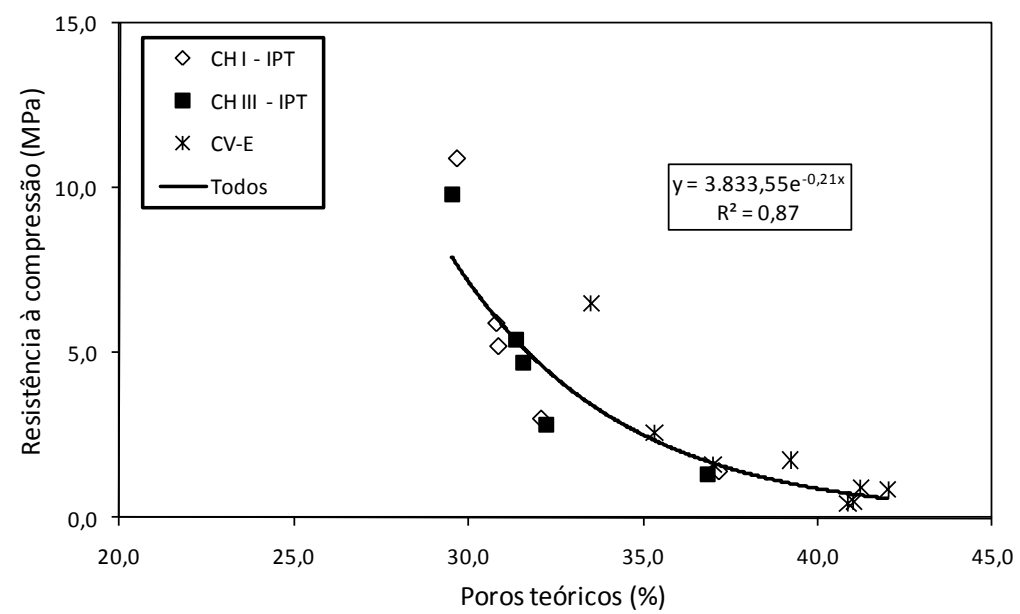

Figura 10 - Correlação entre a resistência à compressão e o volume de poros teóricos calculados 


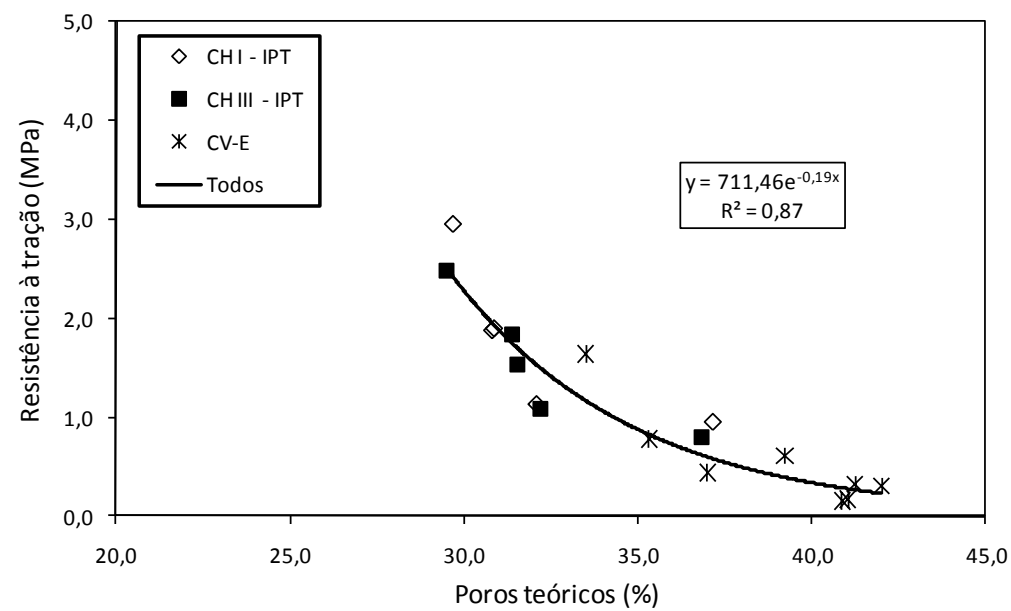

Figura 11 - Correlação entre a resistência à tração na flexão e o volume de poros teóricos

\section{Considerações finais}

A metodologia de estimativa de cálculo de volume de argamassas endurecidas mostrou-se muito favorável para aplicação na previsão de propriedades que definem o comportamento dos revestimentos de argamassa. Os dados obtidos são adequados para a definição de parâmetros de formulação de argamassas industrializadas e/ou produzidas em obra, de forma a minimizar o empirismo tradicional alheio aos conceitos de ciência dos materiais e do entendimento sistematizado do conhecimento.

Porém, além das questões relevantes e favoráveis do trabalho apresentado, considera-se que deve ser registrada a necessidade de continuidade e aprofundamento desta linha de estudo envolvendo aspectos ainda não considerados no cálculo teórico de volume:

(a) aplicação do modelo a resultados de caracterização de argamassas disponíveis na literatura, envolvendo argamassas de diferentes procedências, considerando as variáveis tipos de cimento e de cal, teor de fíler calcário, tipo e morfologia de areia (por exemplo, areia obtida a partir de finos de pedreira e de RCD) e condições de obtenção e cura de argamassas. O foco desta abordagem complementar é o refinamento do modelo teórico, relacionando a porosidade calculada com as propriedades empíricas;

(b) influência dos diversos tipos de retração (BASTOS, 2001) que os revestimentos em argamassa estão sujeitos e sua relação com a dispersão entre os resultados do modelo e os parâmetros empíricos; e

(c) influência da carbonatação, que ocorre no decorrer da vida útil do revestimento de argamassa, na previsão da porosidade obtida a partir do modelo teórico. Como a porosidade do revestimento normalmente diminui devido ao aumento no grau de carbonatação, esse comportamento deverá promover uma dispersão entre os resultados do modelo e os parâmetros empíricos medidos ao longo do tempo (KAZMIERCZAK, 1995; VAN GERVEN et al., 2007).

\section{Referências bibliográficas}

\section{ANTUNES, R. P. N. Influência da Reologia e da \\ Energia de Impacto na Resistência de Aderência de Revestimentos de Argamassa.} 2005. 163 f. Tese (Doutorado em Engenharia de Construção Civil e Urbana) - Escola Politécnica da Universidade de São Paulo, São Paulo, 2005.

\section{ASSOCIAÇÃO BRASILEIRA DE NORMAS \\ TÉCNICAS. NBR 9778: argamassa e concreto} endurecidos: determinação da absorção de água, índice de vazios e massa específica. Rio de Janeiro, 2005.

\section{ASSOCIAÇÃO BRASILEIRA DE NORMAS}

TÉCNICAS. NBR 13276: argamassa para assentamento e revestimento de paredes e tetos: preparo da mistura e determinação do índice de consistência. Rio de Janeiro, 2005.

\section{ASSOCIAÇÃO BRASILEIRA DE NORMAS TÉCNICAS. NBR 13278: argamassa para} assentamento e revestimento de paredes e tetos: determinação da densidade de massa e do teor de ar incorporado. Rio de Janeiro, 2005.

\section{ASSOCIAÇÃO BRASILEIRA DE NORMAS TÉCNICAS. NBR 13279: argamassa para} assentamento e revestimento de paredes e tetos: determinação da resistência à tração na flexão e à compressão. Rio de Janeiro, 2005. 
ASSOCIAÇÃO BRASILEIRA DE NORMAS

TÉCNICAS. NBR 15259: argamassa para assentamento e revestimento de paredes e tetos: determinação da absorção de água por capilaridade e do coeficiente de capilaridade. Rio de Janeiro, 2005.

BASTOS, P. K. X. Retração e Desenvolvimento de Propriedades Mecânicas de Argamassas Mistas de Revestimento. 2001. 172 f. Tese (Doutorado em Engenharia de Construção Civil e Urbana) - Escola Politécnica da Universidade de São Paulo, São Paulo, 2001.

BEAUDOIN, J. J.; FELDMAN, R. F.; TUMIDAJSLI, P. J. Pore Structure of Hardened Portland Cement Pastes and its Influence on Properties. Advanced Cement Based Materials, v. 1, n. 5, p. 224-236, jul. 1994.

KAZMIERCZAK, C. S. Contribuição para a Análise da Eficiência de Películas Aplicadas Sobre Estruturas de Concreto Armado com o Objetivo de Proteção Contra a Carbonatação. 1995. 168 f. Tese (Doutorado em Engenharia de Construção Civil e Urbana) - Escola Politécnica da Universidade de São Paulo, São Paulo, 1995.

MEHTA, P. K.; MONTEIRO, P. J. M. Concreto: microestrutura, propriedades e materiais. São Paulo: IBRACON, 2008. 674 p.

NEVILle, A. M. Propriedades do Concreto. Tradução de Salvador E. Giammusso. 2. ed. São Paulo: PINI, 1997. 828 p.

QUARCIONI, V. A. Reconstituição de Traço de Argamassas: atualização do método IPT. 1998. 188 f. Dissertação (Mestrado em Engenharia de Construção Civil e Urbana) - Escola Politécnica da Universidade de São Paulo, São Paulo, 1998.

QUARCIONI, V. A.; CINCOTTO, M. A. Influência da Cal em Propriedades Mecânicas de Argamassas. In: SIMPÓSIO BRASILEIRO DE TECNOLOGIA DAS ARGAMASSAS, 6., 2005, Florianópolis. Anais... Florianópolis: UFSC; ANTAC, 2005. p. 233-250.
QUARCIONI, V. A. et al. Caracterização da Porosidade de Argamassa Mista Endurecida de Cimento e Cal com Vistas à Durabilidade. In: SIMPÓSIO BRASILEIRO DE TECNOLOGIA DAS ARGAMASSAS, 4., 2001, Brasília, DF. Anais... Brasília, DF: PECC; ANTAC, 2001. p. 471-484.

QUARCIONI, V. A. et al. Aplicação de Método de Ensaio de Permeabilidade ao Ar em Argamassas Moldadas em Laboratório. In: SIMPÓSIO BRASILEIRO DE TECNOLOGIA DAS ARGAMASSAS, 7., 2007, Recife. Anais... Recife: UFPE; ANTAC, 2007. 1 CD-ROM.

QUARCIONI, V. A. et al. Cálculo de Volumes dos Constituintes de Argamassas Mistas de Cimento e Cal Hidratada. In: SIMPÓSIO BRASILEIRO DE TECNOLOGIA DAS ARGAMASSAS, 8., 2009, Curitiba. Anais... Curitiba: UFPR; ANTAC, 2009.

SILVA, N. G. Argamassa de Revestimento de Cimento, Cal e Areia Britada de Rocha Calcária. 2006. 164 f. Dissertação (Mestrado em Construção Civil) - Setor de Tecnologia, Universidade Federal do Paraná, Curitiba, 2006.

VAN GERVEN, T. et al. Effects of Carbonation and Leaching on Porosity in Cement-Bound Waste. Waste Management, v. 27, n. 7, p. 977985, 2007.

\section{Equipe de autores}

Os autores do IPT compõem um grupo multidisciplinar que atua em tecnologia de argamassas. Este trabalho representa a contribuição dessa equipe de especialistas, ou seja, área de química de materiais (Dr. Valdecir A. Quarcioni, Me. Fabiano F. Chotoli e Mário Sergio Guilge) e área de propriedades mecânicas e desempenho de compósitos cimentícios e de argamassas (Dr. Sérgio C. Angulo, Me. Gilberto de Ranieri Cavani e Dra. Alessandra L. Castro). 